\title{
Resenha
}

\section{Fazer-se terrano: por uma metafísica política de gaia}

LATOUR, B. Diante de Gaia: oito conferências sobre a natureza no Antropoceno. Tradução de Maryalua Meyer. São Paulo: Ubu/Ateliê de Humanidades, 2020.

Fernando Silva e Silva ${ }^{1}$

André Araujo ${ }^{2}$

O ano de 2020 viu a publicação de duas obras do filósofo Bruno Latour no Brasil: Onde aterrar? (editora Bazar do Tempo; tradução de Marcela Vieira) e Diante de Gaia (editora Ubu; tradução de Maryalua Meyer). Enquanto aquele busca elaborar uma análise mais imediata do Brexit, da ascensão e vitória de Donald Trump e da crise migratória ${ }^{3}$, este pretende estabelecer os termos para uma nova relação com a Terra em um salto ousado para fora do que o autor chama de Antigo Regime Climático.

A obra possui um percurso particular que merece ser comentado. Sua primeira versão foi na forma de seis conferências ministradas em 2013 na Universidade de Edimburgo no contexto das Gifford Lectures, uma série centenária de conferências sobre teologia natural. Apropriadamente, o título da conferência de Latour foi Facing Gaia: a new enquiry into natural religion [Diante de Gaia: uma nova investigação sobre religião natural]. Vale lembrar quase 90 anos antes, Alfred North Whitehead, pensador fundamental à obra do filósofo francês, proferia suas próprias Gifford Lectures, Process and reality, publicadas em 1929 como Processo e realidade: um ensaio de cosmologia. Ainda antes disso, no começo do século XX,

\footnotetext{
${ }^{1}$ Doutorando em Filosofia (PUCRS).

E-mail: fernandosesilva@gmail.com

2 Doutor em Comunicação e Informação pelo PPGCOM-UFRGS. Pesquisador do GPESC/UFRGS e GPEP/APPH.

E-mail: andrecsaraujo@gmail.com)

3 Para uma resenha da edição brasileira de Onde aterrar?, ver SILVA E SILVA, Rumo ao terrestre! Habitar a Terra no novo regime climático, in Revista rosa, série 1, disponível em: $<$ http://revistarosa.com>. Consultado em: 11/11/20.
} 


\section{2 | Dossiê - Natureza e Sociedade no Antropoceno - Superando a Separação?}

William James, outra importante influência para Latour, realizou as conferências que se tornaram a obra As variedades da experiência religiosa. As conferências de Latour foram publicadas em francês em 2015 em uma edição expandida, com duas conferências adicionais, e em inglês em 2017, também com oito conferências. Essas edições abandonam o subtítulo original das Gifford Lectures e passam a se chamar, traduzindo ambos os títulos, Diante de Gaia: oito conferências sobre o novo regime climático.

A recente tradução brasileira é baseada na obra francesa, mas transforma mais uma vez o subtítulo, temos agora Diante de Gaia: oito conferências sobre a natureza no Antropoceno. A edição brasileira conta com um único material suplementar, um breve prefácio assinado por Latour que condensa alguns dos temas da obra relacionando-os à atual "crise moral, política, sanitária, ecológica e religiosa" (p.9) e os negacionismos que nos impedem de enfrentá-la. Nas páginas a seguir, nos concentramos em sintetizar o que consideramos o centro da obra e o objetivo de Latour com essas conferências, a saber, apresentar a Gaia que ele recruta em sua, e nossa, batalha para transformar as práticas científicas, sensíveis e políticas em tempos de catástrofe climática. Decidimos também nos focar neste termo devido ao seu caráter extremamente equívoco, cuja incompreensão prejudica toda a leitura da obra.

A obra é aberta por quatro epígrafes que colocam em destaque autores cujas teorias são essenciais para a argumentação de Diante de Gaia, a saber, Carl Schmitt, Peter Sloterdijk, James Lovelock e William James. Apesar de que não será o nosso foco, não podemos deixar de comentar que os três primeiros autores, aqueles que têm mais destaque no texto, fizeram ou fazem parte de uma direita conservadora; Schmitt tendo sido, efetivamente, nazista. O que contrasta com as autoras e autores que têm destaque nos agradecimentos: Isabelle Stengers, Eduardo Viveiros de Castro, Donna Haraway, Déborah Danowski, Dipesh Chakrabarty são alguns deles.

Em Diante de Gaia, Latour quer apresentar a atual crise ecológica em todos os seus desdobramentos, caracterizando-a como mais do que uma mera questão ambiental. Para ele, se trata de uma "profunda mutação em nossa relação com o mundo". (p. 24, grifos no original). Esse enunciado pode ser tomado como uma chave de leitura das conferências que compõem a obra, pois um importante eixo do texto é precisamente a investigação da relação humana com o mundo; sua transformação no início da modernidade e hoje; e, talvez o mais importante, o que 
é esse "mundo" de que falamos. A figura mito-científica de Gaia - tomada primeiramente de James Lovelock e Lynn Margulis, e complicada junto de Isabelle Stengers - é uma poderosa orientadora nessa investigação, pois aponta a uma dimensão irredutível da Terra, como explicamos nas próximas páginas. Falar em Gaia é buscar construir, artística, científica e conceitualmente uma figura capaz de expressar os desafios impostos pela crise ecológica e pela era do Antropoceno.

Ao longo de toda sua vida de pesquisa, e marcadamente após a publicação de Jamais fomos modernos (1991), Latour se preocupou em evidenciar o que entendia ser o modo específico aos Modernos de se relacionar com o mundo. Moderna seria toda subjetividade marcada indelevelmente pela distinção entre duas zonas ontológicas: a Natureza e, sua contraparte lógica, a Cultura. O deslindamento desse binômio e as implicações que carrega a articulação de nossa experiência a partir dele é o tema da primeira conferência. A tese de Latour é tão polêmica quanto é objetiva: se chegamos a uma crise ambiental de tal magnitude, a responsabilidade jaz nessa relação com o mundo determinada por uma noção de Natureza inanimada, entendida como um fundo inerte, bruto, impassivo, sobre o qual se desdobram os verdadeiros acontecimentos: a História humana. Tal concepção, para o autor, distorceu de tal maneira a relação com a alteridade do mundo, que se tornou impossível reencontrá-lo. Em suas próprias palavras, "para dizê-lo em uma fórmula bem rápida: para os ocidentais e para aqueles que os imitaram, a 'natureza' tornou o mundo inabitável" (p. 67, grifo no original).

Para Latour, o Antropoceno é uma época que gera confusão, pois, para os Modernos, é como se "o cenário tivesse subido ao palco para compartilhar a trama com os atores" (p. 18). Desenha-se assim um aparente paradoxo, capaz de produzir uma espécie de loucura, em que os domínios da Natureza e da Cultura se fundem e se confundem: de dentro da cosmologia Moderna, se trata da violenta irrupção da natureza na política. Nossa relação com o mundo se modificou, e tentar compreendê-la com os mesmos parâmetros, uma divisão absoluta entre o que seria Natureza ou Cultura, se torna uma tarefa impossível. É para expurgar essa insanidade conceitual que Latour vai apregoar a derrubada do conceito de Natureza. Se a relação se transformou, é preciso refazer também os termos. Como bem afirma, "compreende-se assim que a ecologia não é a irrupção da natureza no espaço público, mas o fim da 'natureza' como um conceito que permite resumir nossas relações com o mundo e pacificá-las” (p. 66-67). 


\section{4 | Dossiê - Natureza e Sociedade no Antropoceno - Superando a Separação?}

A proposição de que o conceito de Natureza (e, por conseguinte, o de Cultura) são formas de resumir e pacificar nossas relações com o mundo é uma constante na obra de Latour. Porém, esses atalhos, que permitiam sempre fazer curto-circuito da política - ora jogando os problemas da vida comum às necessidades incontornáveis da Natureza, ora à diversidade incomensurável da Cultura - são vias condenadas. Apelar a um conceito de Natureza, para Latour, implica em abdicar do pertencimento ao mundo. Essa seria a transformação de nossa relação com o mundo, sua nova configuração: a descoberta de que não podemos escapar dele. Como diz o autor, "[n]ão existe cura para o pertencimento ao mundo. Mas, pelo cuidado, é possível se curar da crença de que não se pertence ao mundo; que essa não é a questão essencial; que o que ocorre com o mundo não nos diz respeito" (p. 31). Se o mundo é agora irredutível à Natureza moderna, de que modo seria possível falar sobre ele, viver nele?

Latour sentencia que estamos diante da necessidade incontornável de repensar essa relação sem, no entanto, apelar para um conceito englobante e totalizante. O filósofo propõe refazer de forma teórica essa divisão, em que, por um lado, haveria uma noção unívoca de Natureza/Cultura e, de outro lado, um conceito simplesmente de mundo, ou de "fazer mundo"4, emprestado de Donna Haraway. Latour convoca essa noção para esse trabalho de reconceituação, pois sublinha a necessidade de um entendimento processual e aberto da constituição do mundo, capaz de, por um lado, conter uma multiplicidade de existentes e, por outro, uma multiplicidade de modos de existir. Jamais se determina e estabiliza de saída o conjunto desses existentes, mas se produz uma relação metamórfica de criação, multiplicação e verificação de seus modos de existir a partir de uma prática experimental.

Essa noção ecoa as proposições de Latour por uma metafísica experimental, desenvolvida explicitamente desde Políticas da Natureza (1999) e agora refinada em Diante de Gaia da seguinte forma: "Essa operação retoma as duas questões canônicas: quais existentes foram escolhidos e quais formas de existência foram preferidas?” (p. 67). Essas duas questões correspondem às duas formas da multiplicidade aludidas anteriormente. É importante destacar aqui que essa metafísica é comparativa por definição. Há infinitas possibilidades de responder a

4 Tradução pouco imaginativa adotada para o termo de worlding de Haraway, talvez mais interessantemente entendido em um verbo: mundificar. 
tais perguntas e cada resposta acaba produzindo coletivos de uma determinada forma. Esses coletivos, ainda que sejam compostos por multiplicidades distintas, coexistem neste mundo. O que Latour quer mostrar, pensando também com a antropologia, é que de certa forma a nossa relação com o mundo precisa, ao mesmo tempo, ser reconstruída a partir de metafísicas que respondem de maneiras distintas a essas questões e à comparação entre elas. Não se responde a essas questões sem uma dimensão pragmática, seja ela científica, filosófica ou religiosa, que acaba por produzir mundos distintos. Esses mundos devem ser capazes de ser comparados e de criar relações sem que necessariamente sejam reduzidos a um termo estável e unívoco, como Natureza.

A verdadeira beleza do termo Antropoceno está em nos aproximar o
máximo possível da antropologia e em tornar menos inverossímil a
comparação dos coletivos afinal liberados da obrigação de se situarem
todos em relação aos demais de acordo com o único esquema de natureza
(singular) e culturas (plural): unidade de um lado, multiplicidade do outro.
Enfim, a multiplicidade está em toda parte! A política pode recomeçar.
(p.23o)

Antes de entrarmos na noção e prática da política reivindicadas por Latour, vale destacar, para ajudar na nossa compreensão, o nexo que ele estabelece com as antigas tábuas de correspondência entre deuses da antiguidade. De acordo com Jan Assman, egiptólogo e estudioso do monoteísmo, havia uma espécie de diplomacia religiosa que permitia com que distintos povos pudessem entrar em uma espécie de comunicação a partir da tradução entre os diferentes deuses de diferentes coletivos. Haveria a possibilidade de criar correspondências entre distintas entidades e assim criar caminhos para uma diplomacia. É apenas com a "divisão mosaica” do monoteísmo que essas tábuas perdem a sua utilidade, pois a comparação se daria entre diferentes formas de idolatria ou paganismo. O deus monoteísta, afinal, seria único, um termo estabilizador que tornaria dispensável essa comparação. Os mundos plurais, assim, acabam sendo reduzidos a uma comparação decaída, como diferentes expressões "culturais" de mundo, decorrentes de um único princípio organizador, estável e transcendente. O nome do verdadeiro deus não poderia ser traduzido em nenhum outro. A essa atitude, Assmann nomeia de contrarreligião. Latour toma emprestado esse termo para fazer uma analogia com a tarefa de comparação dos coletivos. Como ele diz, do ponto de vista dos Modernos, há "a verdadeira natureza contra as múltiplas culturas - está aí a nossa contrarreligião" (p. 281). Em um universo secularizado, o termo estabilizador seria justamente a 


\section{6 | Dossiê - Natureza e Sociedade no Antropoceno - Superando a Separação?}

noção de Natureza. Não adianta comparar metafísicas, pois todos elas seriam apenas "culturas" diferentes - conjuntos de representações tão conflitantes e incomensuráveis quanto, no final das contas, irrelevantes - estabilizadas a partir de uma Natureza única e imutável.

Para Latour, tomar as questões metafísicas como produtoras de mundo nos coloca de volta no espaço das tábuas tradutoras, onde não é a natureza que é primeira e as culturas secundárias, mas precisamente a escolha de existentes e a preferência por determinados modos de existir em detrimento de outros que compõem o mundo, indo em direção, com inspiração nos trabalhos de Eduardo Viveiros de Castro, a uma ideia de multinaturalismo, em oposição a um multiculturalismo.

Esse conceito de mundo avançado pelo filósofo francês se baseia em um projeto político e metafísico de composição entre perspectivas, ideia diametralmente oposta à de um mundo determinado pela emanação de um termo fundamental. Composição aqui deve ser entendida no sentido forte que Latour lhe atribui - em continuidade com a reflexão cosmopolítica de Stengers -, em que nossa relação com o mundo se construirá a partir da possibilidade de comparar construções metafísicas e compor com elas, sem nunca almejar chegar a uma totalidade. O mundo é uma colcha de retalhos, como diria James, um traje de arlequim; um pluriverso, uma tese que ficou em segundo plano na história da filosofia e que agora Latour afirma a urgência de retomá-la. A constituição desse pluriverso tem a ver com uma soma de perspectivas, com traduções e comunicações aberrantes entre nomes diferentes, mas capazes de ressoar uns nos outros. Tradução, comunicação, diplomacia: eis o que Latour vai compreender como a verdadeira dimensão da política no Antropoceno, inclusive chegando a nomeá-la como uma gaiapolítica, a geopolítica agora animada.

Por esse caminho, podemos nos aproximar melhor da noção de Gaia mobilizada por Latour à qual aludimos no início do texto. Sua Gaia seria capaz de articular, ou colocar em curto-circuito, ideias como as de todo e partes. Uma das mais claras definições do conceito está no prefácio para a edição brasileira, em que o autor a define assim:

Gaia não é a natureza virgem. Não é a deusa mãe. Ela não é mãe de coisa nenhuma. Não é sequer um todo, um existente global. É simplesmente a consequência das sucessivas invenções dos viventes que acabaram transformando completamente as condições físico-químicas da terra 
geológica inicial. Hoje, cada elemento do solo, do ar, do mar e dos rios resulta, em grande medida, de modificações, criações e invenções de organismos vivos. Gaia são todos os seres vivos e as transformações materiais que eles submeteram à geologia, desviando a energia do sol para benefício próprio. É nessa rede, nessas trajetórias de seres vivos, que alguns desses viventes - os viventes que somos, que se proclamam humanos, ou seja, pessoas feitas de terra, de húmus, de lama e de cinzas encontram-se irreversivelmente emaranhados. Ou mantemos as condições que tornam a vida habitável para todos os que chamo de terrestres, ou então não merecemos continuar vivendo. É essa a escolha que obriga a nos posicionarmos "diante de Gaia" (p. 10-11)

Apesar da história desse termo, Latour é bastante rápido em desvincular o conceito de Gaia de sua dimensão mitológica ou dos vínculos que mantêm com correntes do pensamento dito esotérico. O filósofo se apropria da discussão inicialmente elaborada por Lovelock, inclusive com um tom quase apologista em relação às teorias do autor, a todo tempo tentando "corrigir" ou justificar suas proposições acerca de Gaia. Um dos casos mais flagrantes dessa atitude é quando Latour empreende uma discussão acerca da relação tensa, interior ao conceito de Gaia, entre as ideias de partes e todo. Para Latour, é importante jamais tomá-la como um todo já composto, mas sim como em processo de composição. Nesse sentido, não haveria nem as partes de um todo almejado, e nem mesmo o resultado como totalidade. Gaia é uma soma sempre em construção. É interessante como Latour irá rejeitar as proposições de Lovelock acerca dessa questão, ainda que retoricamente creditando o estadunidense como criador das mesmas. Quando Latour fala que não se deve aproximar Gaia excessivamente da metáfora de partes e todo proposta pelo organismo, suas proposições se aproximam muito mais das desenvolvidas por Deleuze e Guattari em O Anti-Édipo, por exemplo, ou da Gaia indiferente e indeterminada de Stengers, do que da conceituação elaborada por Lovelock, ainda que o filósofo francês prefira citar este em detrimento daqueles.

De todo modo, o que devemos compreender é que, para Latour, Gaia não é uma deusa transcendente ou uma espécie de divindade tradicional que deveríamos adorar. Ao contrário, Gaia é uma figura e um conceito imanente: trata-se do nome dado ao efeito produzido pelas infindáveis conexões que se dão entre os mais diversos elementos terrestres vivos e não vivos que criaram as condições de habitação neste planeta. Latour dá o nome de Gaia a essa frágil rede de relações na qual estamos invariavelmente emaranhados. Se retomamos as proposições acima colocadas, podemos dizer que Gaia é o termo diplomático estabelecido entre os diversos coletivos que habitam o planeta. 


\section{8 | Dossiê - Natureza e Sociedade no Antropoceno - Superando a Separação?}

Assim como todo documento, e espaço, diplomático, Gaia é também frágil. Se parece grande demais, em uma escala que nos transcende, é muito mais pela quantidade e multiplicidade das relações estabelecidas, em direções muitas vezes contraditórias e de difícil apreensão, do que por existir em uma escala absolutamente distinta. $\mathrm{O}$ fato de que os organismos vivos conseguiram manter um conjunto de relações mútuas e com uma gama de diversos elementos não vivos é um processo construído historicamente, uma gaiahistória, e não uma espécie de totalidade pressuposta a priori. É nesse sentido que Gaia não deve ser tomada como um conceito transcendente, como se houvesse uma situação de partida que apenas se ajusta de acordo com as interações entre os viventes. Pelo contrário, Gaia é o que emerge dessas relações, é o nome desse enorme agenciamento de agenciamentos. Aqui vemos com clareza a ideia de composição que Latour movimenta ao longo de todo livro, buscando compreender e apresentar Gaia nessa posição paradoxal em que ela é, ao mesmo tempo, causa e efeito desse mundo coletivo em que a vida na Terra é possível.

Como apontamos no início desta resenha, é através de uma prática de cuidados que Latour entrevê a possibilidade de aprendermos a nos relacionar com o mundo, e não com a natureza. Trata-se de "descobrir um percurso de cuidados" (p.31) que torne possível elaborar respostas totalmente outras a perguntas antigas como "Quem somos nós, nós, que ainda nos chamamos de "humanos"? Em qual época nos encontramos [...]? Onde residimos? Qual gênero de território, de solo, de lugar somos aptos a habitar e com quem estamos prestes a coabitar?” (p. 70). A descoberta de que poderíamos ser algo outro que humanos - talvez Terrestres que habitam a Terra e não a Natureza como os Modernos - é um passo fundamental de um percurso cujo fim não conhecemos. Esperamos, todavia, que esse percurso poderá não só nos ajudar a ingressar no Antropoceno sem que colapsemos na barbárie, mas também inventar formas de viver bem, aprendendo com aqueles e aquelas que nunca viveram fora deste mundo e cujas vidas foram (quase) obliteradas pelo fronte de modernização, mas que, apesar disso, insistem em fazer do mundo um pluriverso. 